\title{
A centralidade da agricultura familiar nas questões relacionadas à sustentabilidade do meio ambiente em pequenas propriedades rurais
}

\author{
The centrality of Family Agriculture in issues related to the sustainability of the environment in small rural \\ properties
}

Verenice Zanchi

Universidade de Santa Cruz do Sul - UNISC - Santa Cruz do Sul - Rio Grande do Sul - Brasil

\author{
Mariana Barbosa de Souza \\ Universidade de Santa Cruz do Sul - UNISC - Santa Cruz do Sul - Rio Grande do Sul - Brasil
}

\section{João Paulo Reis Costa}

Universidade de Santa Cruz do Sul - UNISC - Santa Cruz do Sul - Rio Grande do Sul - Brasil

\begin{abstract}
Resumo: O presente texto propõe uma reflexão acerca dos temas desenvolvimento regional, agricultura familiar, sustentabilidade e turismo rural. Para tanto propomos uma análise a partir de dois roteiros de turismo rural situados na região do Vale do Rio Pardo, quais sejam, Rota Germânica do Rio Pardinho e Roteiro Caminhos da Imigração, visto que, a manutenção das estruturas do turismo rural no Vale do Rio Pardo perpassa as discussões acerca da sustentabilidade do meio ambiente. A pesquisa, de caráter qualitativo, apoiou-se na abordagem dialética, visando compreender o papel da agricultura familiar e do turismo rural como caminho para a sustentabilidade ambiental. Com base na análise dos dados, constatamos que existem, entre os participantes dos roteiros de turismo rural da região, iniciativas de conservação e preservação do meio ambiente.
\end{abstract}

Palavras-chave: Desenvolvimento regional. Agricultura familiar. Sustentabilidade. Turismo rural.

Abstract: The present text proposes a reflection about the regional development, the family agriculture, the sustainability and the rural tourism. For that, we propose an analysis based on two routes of rural tourism located in the region of the Rio Pardo Valley, namely, the "Rota Germânica do Rio Pardinho" and the "Roteiro Caminhos da Imigração", since the maintenance of the structures of rural tourism in the Rio Pardo Valley permeates discussions about the sustainability of the environment. The qualitative research was based on the dialectical approach, aiming to understand the role of family farming and rural tourism as a path to environmental sustainability. Based on the analysis of the data, we verified that among the participants of the rural tourism routes of the region, initiatives of conservation and preservation of the environment exist.

Keywords: Regional development. Family agriculture. Sustainability. Rural tourism. 


\section{Introdução}

Debates e estudos em torno de temas como desenvolvimento regional, agricultura familiar, sustentabilidade e turismo rural vêm recebendo cada vez mais atenção, no decorrer das três últimas décadas. Tanto no meio acadêmico, quanto no público ou no privado, iniciam-se discussões e ações que visam a reativação do sentimento de pertencimento, bem-estar, bem como da permanência dessas famílias no meio rural. Surgem iniciativas da sociedade em parceria com poder público a fim de garantir que o desenvolvimento regional ocorra de forma sustentável, a exemplo da implementação de roteiros de turismo rural.

Nesse contexto, abordamos os exemplos da Rota Germânica do Rio Pardinho, situada entre os municípios de Santa Cruz do Sul e Sinimbu, e do Roteiro Caminhos da Imigração, no município de Santa Cruz do Sul. Ambos criados pelas comunidades com o incentivo do poder público e da Associação de Turismo da Região do Vale do Rio Pardo - ATURVARP, não necessariamente nessa ordem. Cabe destacar que os dois roteiros (nesse artigo decidimos utilizar o termo "roteiro" para definir o objeto de análise, mas originalmente alguns se autodenominam "rotas", o que foi mantido) têm em comum o objetivo de promover o desenvolvimento da região de forma sustentável, o que ocorre quando as famílias optam pela diversificação da propriedade, por meio da implementação da atividade turística.

Destacamos a importância de identificar as particularidades da região e entendê-las como potencialidades a fim de reduzir as desigualdades sociais e promover a equidade. Tais ações estão diretamente ligadas à concepção de desenvolvimento regional sustentável, defendida por Milton Santos (1997).

Nesse encadeamento, o território é configurado pelos pequenos agricultores familiares que participam dos roteiros para compor o produto turístico. O mesmo ocorre com a cultura local, considerada como bem imaterial dessa comunidade.
Portanto, nos apropriamos do método de abordagem dialética para compreender os conflitos e contradições que permeiam a realidade, posto que pesquisar significa procurar respostas para as indagações propostas. A abordagem dialética une, "[...] a proposta de analisar os contextos históricos, as determinações socioeconômicas dos fenômenos, as relações sociais de produção e de dominação com a compreensão das representações sociais". (MINAYO, 2010, p. 24).

A fonte primordial da investigação qualitativa é a palavra que expressa a fala cotidiana. Assim, por meio da pesquisa qualitativa, entendemos que há uma relação provisória, dinâmica e repleta de especificidades entre o mundo real e o sujeito, isto é, um vínculo indissociável entre o mundo objetivo e a subjetividade do sujeito, que não pode ser traduzido em números. Sendo ela descritiva, o processo e seu significado são os focos principais de abordagem. (MINAYO e SANCHES, 1993).

Nesse sentido, para alcançarmos os objetivos, utilizamos a pesquisa qualitativa, com o uso das seguintes técnicas: entrevista semiestruturada, combinando perguntas fechadas e abertas e entrevista em profundidade, na qual o entrevistado foi convidado a falar livremente. Buscamos, ainda, dados secundários junto aos bancos de dados do Instituto Brasileiro de Geografia e Estatística - IBGE e da Fundação de Economia e Estatística - FEE.

Apresentaremos a seguir os conceitos de desenvolvimento regional agricultura familiar, sustentabilidade e turismo rural, à luz dos quais analisamos a região e os dois roteiros em destaque, encerrando com algumas considerações finais.

\section{0 desenvolvimento regional, a agricultura familiar, a sustentabilidade e o turismo rural}

O desenvolvimento regional aqui apresentado alinha-se à visão de Sen (2000, p. 10) acerca do desenvolvimento, na qual o autor aponta que "o desenvolvimento consiste na eliminação de privações de liberdade que limitam as escolhas $e$ as 
oportunidades das pessoas de exercer ponderadamente sua condição de agente".

Nessa perspectiva, para Sen (2002), os atores estão ativamente envolvidos na configuração de seu próprio destino e não apenas esperando passivamente que programas governamentais de desenvolvimento os beneficiem. Dessa liberdade ainda faz parte o processo de participação democrático, no qual os atores, na condição de "agentes", participam de debates políticos e decidem onde as verbas serão alocadas.

Cabe destacar que no Brasil o desenvolvimento apresenta duas fases: uma anterior e outra a partir de 1960. Na primeira, não havia uma estratégia de desenvolvimento e as regiões brasileiras não mantinham ligações. Ocorria apenas a integração das áreas produtoras aos fluxos mundiais de comércio. $\mathrm{Na}$ segunda, o mercado nacional passou a contar com políticas de desenvolvimento regional, que visavam em um primeiro momento, estimular a industrialização e posteriormente reduzir conflitos fundiários no Nordeste e colonizar as fronteiras, o que também garantia uma ocupação geopolítica. (ACSELRAD, 2008).

Já a partir dos anos 1970, o desenvolvimento regional ganhou novo enfoque, passando a ser visto de dentro para fora, ou seja, endógeno. Segundo Benko (1999, p. 288), trata-se de "[...] uma estratégia de diversificação e de enriquecimento das atividades sobre um dado território com base na mobilização de seus recursos (naturais, humanos e econômicos) e de suas energias".

Após as mudanças da divisão social do trabalho da década de 1990, é pertinente considerar que "[...] houve perda de dinamismo econômico de algumas especializações regionais, o que reduziu potenciais localizados de empuxe e arraste intersetorial e de desenvolvimento regional [...]". (BRANDÃO, 2004, p. 66).

Também Benko (1999) aponta que o desenvolvimento de uma região se deve, principalmente, a sua dinâmica interna, ou seja, a fatores endógenos. Brandão (2004, p. 71) aponta que,

\begin{abstract}
O grande desafio é construir simultaneamente, e dar unidade, aos seguintes pares (por vezes antagônicos): eficiência/equidade;

especialização/diversificação produtivas; crescer/redistribuir renda e riqueza, entre outros. Isto é, construir permanentemente integração e coesão produtiva, social, política, cultural, econômica e territorial.
\end{abstract}

Boisier (1996) defende que o desenvolvimento de um território depende da existência, interação e articulação de seis elementos - atores, instituições, cultura, procedimentos, recursos e entorno, dos quais depende o sucesso ou o fracasso da região.

Ainda para Brandão (2004, p. 70) o desenvolvimento é um processo resultante de variadas e complexas interações sociais, e que

[...] esse processo deve promover a ativação de recursos materiais e simbólicos e a mobilização de sujeitos sociais e políticos buscando ampliar o campo de ação da coletividade, aumentando a sua autodeterminação e liberdade de decisão. Neste sentido, o verdadeiro desenvolvimento exige envolvimento e legitimação de ações disruptivas e emancipatórias, envolvendo, portanto, tensão, eleição de alternativas e construção de trajetórias históricas, com horizontes temporais de curto, médio e longo prazos.

No contexto do desenvolvimento regional, a relação com o território ocorre na medida em que a sociedade molda esse lugar de acordo com suas necessidades e insere nele suas características, fazendo despertar em seus agentes o sentimento de pertencimento. Assim, o turismo pode ser de extrema importância para o desenvolvimento regional, principalmente porque, para alcançar seu objetivo central - atrair o turista -, apropria-se dos bens materiais e imateriais dos atores locais. Esses atores locais, ao desenvolverem a noção de pertencimento, tornam-se agentes que se apropriam, que usam o território e, neste contexto, a natureza e o meio natural não são mais vistos como meros recursos. (SANTOS, 1997).

Portanto, o território é entendido como espaço usado e apropriado, no qual, sociedade e natureza coexistem, ou seja, os elementos do social e do natural são inseparáveis. 
Santos (2000, p. 104) destaca que o "território usado [...] é tanto o resultado do processo histórico quanto a base material e social das novas relações humanas", o que, por esse ponto de vista, "[...] permite uma consideração abrangente da totalidade das causas e dos efeitos do processo sócio territorial".

Por assim dizer, de um lado se revela a estrutura global da sociedade e do outro a complexidade do seu uso. Essa perspectiva leva em conta todos os atores e considera que cada um é um agente que se apropria, que usa o território de forma complexa e diferenciada. E é nesse território, envolvido por relações de poder, processos produtivos, evidenciações culturais, que 0 desenvolvimento acontece. (ETGES, 2005).

Também Pecqueur (2009) ressalta a importância de valorizar o que está no território, da economia baseada nele, ou seja, agregar valor ao produto em função do território em que ele é feito, promovendo a consciência ecológica e a responsabilidade social.

No início da década de 1960 ocorreu o despertar da consciência ecológica e esta ganhou voz nas décadas seguintes. Foi a partir daí que a sustentabilidade e 0 desenvolvimento se entrelaçaram. (BURSZTYN e BURSZTYN, 2012). Assim, as questões da sustentabilidade foram pouco a pouco permeando as teorias de desenvolvimento.

Souza (2000, p. 145) afirma que "há um forte consenso de que o modelo de desenvolvimento sustentável $^{1}$ deveria ser endógeno e local, preservando e valorizando a participação popular, o conhecimento e a cultura dos povos envolvidos em seu processo [...]".

Nesse sentido, cabe inferir que a sustentabilidade é aqui entendida como a necessidade de sustentar a vida no planeta terra. $\mathrm{E}$ por isso, traçar e implementar planos que contribuam para tal são cada vez mais relevantes, uma vez que o

\footnotetext{
1 Entendido aqui de acordo com a definição do relatório de Brundtland, segundo a qual "o desenvolvimento sustentável é aquele que atende às necessidades do presente sem comprometer a possibilidade de as gerações futuras atenderem a suas próprias necessidades". (CARVALHO e BARCELOS, 2010, p. 101).
}

homem, como ser social, reforça laços e se associa, formando organizações, por meio das quais dinâmicas de desenvolvimento regional podem ser implementadas. A formação e atuação dos Conselhos Regionais de Desenvolvimento - COREDES, no Rio Grande do Sul, são exemplos da importância e da necessidade de planejamento e organização em âmbito regional. Outro exemplo é a Associação criada para formar a Rota Germânica do Rio Pardinho, roteiro de turismo rural entre os municípios de Santa Cruz do Sul e Sinimbu, no Vale do Rio Pardo - RS.

Nessa perspectiva, é importante aprofundar o conceito de sustentabilidade, ou sustentabilidade viável. Isso porque, de acordo com Bursztyn e Bursztyn (2012) a sustentabilidade pode ser forte ou fraca. Os autores definem que

O conceito de sustentabilidade fraca se refere ao equilíbrio entre as esferas, econômica, social e ecológica. Pressupõe a possibilidade de compatibilizar a dinâmica das atividades econômicas com a justiça social e o respeito às condições do mundo natural, de modo a que estas se mantenham no longo prazo. (BURSZTYN e BURSZTYN, 2012, p. 52).

Souza (2000, p. 155) infere que a sustentabilidade fraca "[...] depende mais da manutenção do capital total (natural mais artificial)" do que exclusivamente do natural. Enquanto que a sustentabilidade forte depende apenas da "manutenção do nível de capital natural".

A sustentabilidade forte advém da corrente da ecologia profunda, a qual apregoa que o ser humano, na busca pelo seu bem-estar por meio das mais diversas atividades, tais como: a caça e a pesca, o cultivo de terras, a construção de cidades e a industrialização, provoca algum tipo de impacto negativo ao meio ambiente. (BURSZTYN e BURSZTYN, 2012). Por conseguinte,

O conceito de sustentabilidade forte tem como fundamento a constatação científica de que qualquer ação humana se dá no âmbito dos limites do Planeta, ou da biosfera, onde a humanidade habita. Isso inclui a vida social em geral e as atividades econômicas em particular. (ADAMS, 2006, apud BURSZTYN e BURSZTYN, 2012, p. 51). 
Contudo, segundo os autores pensar na aplicabilidade de uma sustentabilidade forte seria retornar à condição de nômade-coletor, além de pressupor o decréscimo da população. Já para Carvalho e Barcelos (2010, p. 100), a sustentabilidade forte pressupõe que o capital natural "[...] deva ser mantido constante, no todo ou em pelo menos uma parte do mesmo, o chamado capital natural crítico". Tem-se assim, que a sustentabilidade fraca é a forma mais viável de sustentabilidade na atualidade, contudo é imperativa a necessidade de impor limites de uso, ou seja, definir os níveis de capital natural crítico. (CARVALHO e BARCELOS, 2010).

Portanto, para o uso sustentável do meio ambiente Bursztyn e Bursztyn (2012, p. 53) definiram três categorias de suporte, quais sejam: a) "técnicas de previsão e de apoio à tomada de decisão, como cenários, avaliação ambiental ou análise custobenefício"; b) "instrumentos de mensuração, como pegada ecológica e sistemas de indicadores em geral"; c) "o desenvolvimento de uma base científica sobre limites do meio natural é condição prévia ao estabelecimento das regras para o seu uso. Dado que o ambiente é um dos elementos do tripé, é preciso conhecer a sua capacidade de suporte e resiliência". Sendo que na visão dos autores, "a capacidade de suporte está associada ao limite de utilização de um determinado meio (ecossistema) sem que suas propriedades sejam perturbadas ao ponto de comprometer a regeneração natural", ou seja, para definir o uso (BURSZTYN e BURSZTYN, 2012, p. 54).

Assim sendo, com relação ao turismo,

O conceito de capacidade de suporte serve, por exemplo, para orientar decisões sobre a capacidade de carga de áreas de visitação [...] e para o estabelecimento de parâmetros para conservação e áreas de vegetação natural em pastagens ou agricultura. Uma vez entendidos os limites, é possível definir regras de uso [...]. (BURSZTYN e BURSZTYN, 2012, p. 54).

E associada à capacidade de suporte está a resiliência - entendida aqui como capacidade de regeneração do meio ambiente - que uma vez combinadas criam a possibilidade de uso sustentável do meio natural. (BURSZTYN e BURSZTYN, 2012).

Por isso, Bursztyn e Bursztyn (2012, p. 64) asseveram a importância de trocar o crescimento econômico pela sustentabilidade, ou seja, "[...] passar da busca por mais (em termos de produção e consumo, e consequentemente de apropriação de recursos naturais) para o paradigma do melhor, ou seja, melhorar a qualidade de vida sem aumentar o consumo". Latouche (2012, p. 49) corrobora essa visão ao inferir que "a verdadeira riqueza pode ser também 0 fato de ter amigos e fazer coisas interessantes etc". Aponta ainda a importância de "trabalhar menos para viver melhor, para redescobrir o sentido da vida". (LATOUCHE, 2012, p. 51).

No contexto de um desenvolvimento regional mais sustentável, o turismo rural tem contribuído como alternativa de enfrentamento às adversidades econômicas, principalmente na Agricultura Familiar ${ }^{2}$.

Essas famílias enfrentam dificuldades decorrentes do processo de mecanização da produção, mais precisamente da Política de Crédito Agrícola Brasileira das décadas de 1970 e 1980, a qual estava direcionada a atender médios e grandes produtores. Conforme Schneider (1999) e Silva e Campanhola (2000), os impactos negativos dessas políticas podem ser encontrados em muitos municípios do Estado do Rio Grande do Sul.

Por isso, na década de 1990, foi promovido um debate sobre o turismo, entre governo, iniciativa privada, academia e sociedade, do qual resultaram profundas mudanças nas políticas públicas do setor.

\footnotetext{
2 Agricultura Familiar referida, diz respeito aos sujeitos contemplados pela Lei 11.326/06, a qual reconhece a agricultura familiar como segmento produtivo e representa um novo marco para as políticas públicas destinadas ao desenvolvimento rural, desde a fase de elaboração até a implementação, execução e gestão de recursos. Estabelece como parâmetro o agricultor ou agricultora familiar que não tenha propriedade maior do que quatro módulos fiscais, que utilize predominantemente mão-de-obra da própria família nas atividades econômicas do seu empreendimento, que tenha renda familiar predominantemente originada de atividades econômicas vinculadas ao próprio estabelecimento ou empreendimento, entre outros. Também acrescentamos os silvicultores, aquicultores, extrativistas artesanais, pescadores artesanais, povos indígenas, integrantes de comunidades remanescentes de quilombos rurais e demais povos e comunidades tradicionais. Todos incluídos pela lei $n$ 12.512, de 2011. Disponível <http://www.mda.gov.br/sitemda/noticias/sancionada-lei-daagricultura-familiar>. Acesso em: 11 set. 2016.
} 
Desse debate, resultou o Plano Nacional de Municipalização do Turismo - PNMT, que tem como objetivo melhorar 0 produto turístico em âmbito municipal. (BENI, 2006).

A partir desse contexto de mudanças da década de 1990, o turismo foi introduzido na região do Vale do Rio Pardo com o intuito de contribuir com o desenvolvimento da região, reduzir o desemprego e o despovoamento das áreas rurais, as quais têm no cultivo do tabaco uma de suas principais atividades, gerando uma grande dependência da região em relação ao setor fumageiro.

O Vale do Rio Pardo destaca-se com 19,92\% de todo o fumo em folha produzido no Brasil (no período de 2008 a 2012). [...]. No caso do Vale do Rio Pardo, pode-se destacar inicialmente a dependência econômica gerada por este sistema, na medida em que a economia dos municípios encontra-se amplamente alicerçada sobre a produção do tabaco. Prova disso é que a participação do tabaco no Valor Bruto da Produção agrícola dos municípios do Vale do Rio Pardo é, em média, de 61,5\% (IGBE, 2010), o que caracteriza o tabaco como uma monocultura na região. (GOMES, 2014, p. 17).

Esses dados mostram a dependência da economia da região do segmento do tabaco, tanto da indústria de beneficiamento da matéria prima quanto da indústria do cigarro. À luz desses dados, estabeleceu-se na região um certo consenso, fortemente fomentado pelos setores industriais, políticos e pela mídia, de que a única atividade economicamente viável para a agricultura familiar seria a produção do tabaco. Nesse contexto, o turismo rural vem se apresentando como uma oportunidade de diversificação de renda nas propriedades familiares.

O turismo rural surge para os agricultores familiares não só como mais uma possibilidade de trabalho e renda, mas como possibilidade de viver melhor. Segundo Beni (2002), em um contexto de desenvolvimento regional, a atividade turística gera a circulação de divisas entre uma região e outra.

É nesse contexto de valorização do meio rural, das potencialidades da região a partir do território e de busca pela sustentabilidade, que serão analisados a Rota Germânica do Rio Pardinho e o Roteiro Caminhos da Imigração.

\section{Turismo rural: uma alternativa sustentável para a agricultura familiar}

A região do Vale do Rio Pardo, tão marcada pela cultura do tabaco, um sistemas integrado que historicamente produz dependência econômica dos agricultores familiares, por meio da ação das grandes empresas transnacionais e seus "pacotes tecnológicos", que dominam todo processo produtivo, de beneficiamento e de comercialização torna-se refém de um processo econômico que pouco ou quase nada dialoga com outras possibilidades concretas de desenvolvimento, como a produção de alimentos, o turismo rural, entre outros.

Parte-se do pressuposto de que cada região compreende uma determinada porção do espaço com características naturais específicas, moldada a partir de seu processo de formação histórico-cultural, do qual deriva sua identidade social, econômica e política.

A região do Vale do Rio Pardo está situada na porção centro/setentrional do Estado do Rio Grande do Sul, sendo este o estado mais meridional do Brasil. Tem sua origem e sua formação econômica e social decorrente da colônia de Rio Pardo, a qual, no século XVIII constituiu-se num dos mais antigos espaços de ocupação e domínio português. (VOGT, 2001). Com a vinda de imigrantes alemães, italianos, poloneses, entre outros, terras foram distribuídas para o desenvolvimento de atividades agrícolas, em regime de trabalho familiar. (FEE, 2015).

Essa forma de ocupação, a partir do século XIX, originou uma produção diversificada nessas pequenas propriedades rurais, criou uma distribuição de renda menos concentrada e resultou em uma rede urbana formada por pequenos núcleos. (FEE, 2015), características que pouco mudaram com o passar do tempo. (SEPLAG, 2015).

Destarte, é possível inferir que a diversificação nas pequenas propriedades da região do Vale do Rio Pardo remonta à colonização do Estado pelos 
imigrantes, que vieram com o propósito de ocupar e cultivar as terras até então cobertas por mata nativa. Atualmente, a diversificação de atividades nas pequenas propriedades rurais contribui para 0 aumento e redistribuição da renda e com a segurança alimentar dos agricultores familiares e da comunidade. Inclusive com o meio ambiente, por meio do uso sustentável da terra.

Isso posto, cabe destacar que dentre os agricultores familiares que vem buscando meios de diversificar econômica e produtivamente suas propriedades, implementando a atividade turística, encontramos alguns que, com o objetivo de viver melhor optaram por reduzir ou mesmo eliminar, o cultivo do tabaco, o que ratifica os apontamentos de Latouche (2012). Sen (2000) considera que a diversificação contribui com a redução da dependência das famílias de uma única cultura e tem grandes chances de melhorar a renda familiar. Para Almeida e Riedl (1998), o turismo rural, enquanto atividade de diversificação da propriedade, impõe-se contra os alicerces tradicionais da agricultura, que subjugam a produção que está exposta ao risco, às incertezas e à exaustão.

Segundo Cristóvão (2002, p. 81), o desenvolvimento rural está ligado à diversificação, sendo que [...] a ideia de diversificação da economia rural decorre, cada vez mais, do reconhecimento de que o espaço rural é bem mais do que um simples fornecedor de matérias primas. É, no fundo, um espaço multifuncional. Perceber o espaço rural e sua comunidade como um lugar multifuncional implica em valorizar seus recursos e reconhecer seu potencial endógeno. (CRISTÓVÃO, 2002). Também Blos (2000) aponta para o desenvolvimento dos recursos endógenos, ou seja, do turismo rural, como alternativa para gerar melhoria da qualidade de vida, produção econômica e serviços.

$\mathrm{Na}$ região do Vale do Rio Pardo foram identificados cinco roteiros de turismo rural, contudo esta pesquisa está focada em dois, a Rota Germânica do Rio Pardinho e o Roteiro Caminhos da Imigração. A Rota Germânica de Rio Pardinho foi lançada em 26 de junho de 1998, com o nome de Roteiro Rural,
Colonial e Ecológico de Rio Pardinho. Inicialmente faziam parte do roteiro dez atrativos. O roteiro tem como finalidade manter a tradição, preservando assim os hábitos e costumes originais dos colonizadores do século XIX, a arquitetura, a gastronomia e o artesanato, característicos da colonização alemã. Dentre os atrativos oferecidos ao turista estão a vida tipicamente colonial, belas paisagens formadas por um conjunto de rios e vales, cafés coloniais, pousadas, restaurantes, lojas de artesanato, entre outros. Oferece, ainda, a oportunidade de convívio com as famílias, acompanhando o seu dia a dia nas propriedades.

O roteiro atualmente conta com 17 atrativos. Sendo oito no município de Santa Cruz do Sul: Cervejaria Heilige, Barragem Lago Dourado, Mosteiro da Santíssima Trindade, Igreja Imigrante, Cucas Gressler, Salão Waechter, Basteleihaus (Casa de Trabalhos Manuais) e Restaurante Vale Verde. E nove em Sinimbu: Artehaus, Igreja Nossa Senhora da Glória, Artesanato Sinimbu, Quiosque, Floricultura Wendland, Gruta Nossa Senhora de Lurdes, Igreja Evangélica de Sinimbu, Agroindústria Panke e RPPN UNISC - Reserva Particular do Patrimônio Natural.

Em termos de propriedades que diversificaram as atividades e implementaram o turismo, buscando a sustentabilidade, destacamos a Basteleihaus (Casa de Trabalhos Manuais) e a Artehaus. Ambas trabalham com artesanato sustentável, ou seja, utilizam sementes, palha de milho, latas e outros materiais reciclados para a confecção das peças. Cabe apontar que a família que mantém a Artehaus, reduziu o plantio de tabaco após iniciar essa nova atividade.

\section{Figura 1 - Basteleihaus e Salão Waechter}

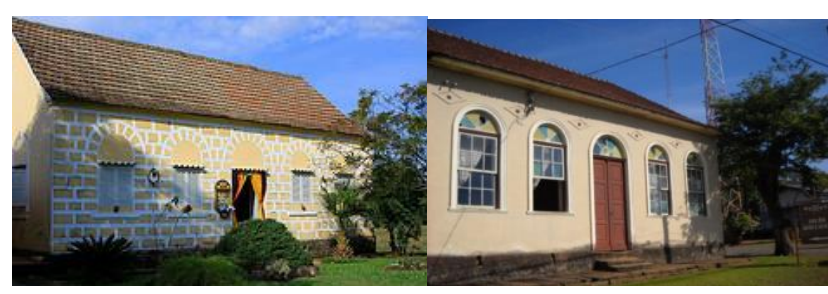

Fonte: ATURVARP, 2015 e ZANCHI, 2012. 
A família Pranke, após a instalação da agroindústria na propriedade e posterior entrada no roteiro, reduziu a produção de tabaco, atualmente produz e comercializa os mais diversos tipos de cucas, tortas, bolos e pães.

O mesmo caminho foi adotado pela família proprietária da Cucas Gressler, que comercializa cucas e produtos coloniais como Schimier, linguiça, tortas, rocamboles, bolachas, pão caseiro entre outros produtos da gastronomia típica alemã.

A Reserva Particular do Patrimônio Natural RPPN da Universidade de Santa Cruz do Sul UNISC, preserva uma área 221,39 hectares e conta com áreas destinadas à preservação, à pesquisa científica, projetos de educação ambiental e atividades de ecoturismo. No centro de visitantes são realizadas palestras relacionadas à educação ambiental e conservação do meio ambiente e ocorrem visitas, nas quais são realizadas trilhas interpretativas e é distribuído material explicativo sobre a reserva e sobre a fauna e flora da RPPN e da região.

\section{Figura 2 - RPPN UNISC}

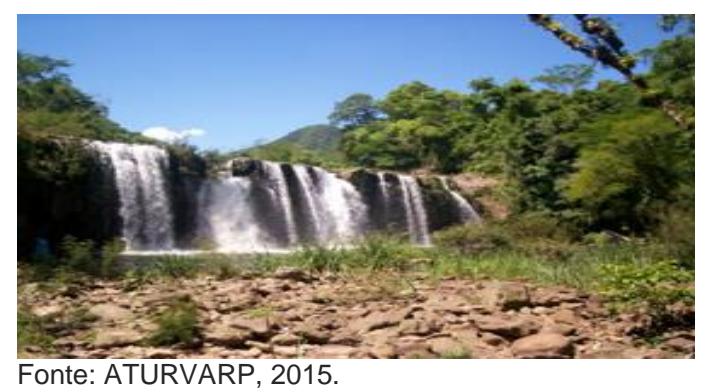

Figura 3 - Mirante da Boa Vista e Pousada Camponesa

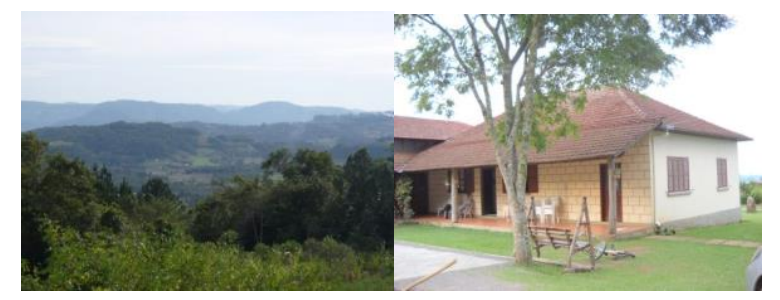

Fonte: ATURVARP, 2015 e ZANCHI, 2012.

O Roteiro Caminhos da Imigração, inaugurado em 19 de fevereiro de 2000, contava com nove atrativos. Tendo por objetivo manter a tradição, a arquitetura, a gastronomia e 0 artesanato, característicos da colonização alemã do século XIX. Localiza-se entre os distritos de Boa Vista e de Linha Santa Cruz, ambos no município de Santa Cruz do Sul. Vinte atrativos compõem o roteiro: Aeroporto Luiz Beck da Silva, Cooperativa Agrícola Linha Santa Cruz, Residência de José Germano Frantz, Casa Comercial e Salão de Bailes Frantz - Associação de Damas, Capril Boa Vista, Casa em estilo enxaimel, Cemitério Evangélico de Alto Linha Santa Cruz, Centro Esportivo Recreativo Cultural Chácara Bauermann, Centro Histórico de Boa Vista, Cruz dos Assmann, Escola Estadual Professor Affonso Pedro Rabuske, Família Fritz e Frida, Igreja Evangélica de Confissão Luterana do Brasil de Linha Andrade Neves, Igreja Evangélica de Alto Linha Santa Cruz, Local da primeira missa, Mirante de Boa Vista, Paróquia Santos Mártires das Missões de Linha Santa Cruz, Pousada Camponesa, Rua José Germano Frantz, Sítio Sete Águas.

Nesse roteiro destacamos a propriedade na qual está estabelecida a Pousada Camponesa, que abandonou completamente o cultivo do tabaco. Além de que todo o cultivo da propriedade está voltado para a produção orgânica. Preservam ainda as fontes naturais de água existentes na propriedade e a mata nativa, em que são realizadas trilhas pelos visitantes.

O Sítio 7 águas também reduziu sua produção de tabaco após a implementação da atividade turística na propriedade, e mantém ainda uma horta da qual os visitantes podem "colher e levar". Conservam as nascentes e parte da mata nativa, principalmente nas margens do rio que recorta a propriedade.

O Capril da Boa Vista abre sua propriedade para que o turista possa acompanhar a lida diária com os cabritos.

Essas são algumas experiências que relacionam o turismo rural com atividades próprias da Agricultura Familiar, voltada para a produção da subsistência e a comercialização de excedentes, portanto, preocupada com o meio ambiente, com o que produz, e com a preservação de valores culturais 
trazidos de gerações passadas. Dessa forma promovem a aproximação dos visitantes com a realidade dos agricultores familiares empreendedores do turismo rural, tanto por meio de empreendimentos individuais, ou por meio de rotas organizadas entre os poderes públicos e as associações de turismo rural.

\section{Considerações finais}

Percebemos que os agricultores participantes dos roteiros têm buscado contribuir com a promoção do desenvolvimento regional sustentável, porque identificaram na paisagem e na cultura local, particularidades, as quais foram convertidas em potencialidades, ou seja, produto turístico. Constatamos que eles têm exercido, em certa medida, o papel de agentes, ao participarem, tanto das reuniões da associação de seu respectivo roteiro, quanto das proporcionadas pela ATURVARP.

Verificamos, entre os agricultores familiares entrevistados, a perspectiva de redução da produção de tabaco ou a sua substituição pela atividade turística. A preocupação com a sustentabilidade ambiental aparece ainda por meio da preservação das nascentes e da mata nativa e quando reconhecem a sua importância, tanto para si, suas famílias, bem como para a comunidade. Também, percebemos uma forte preocupação em manter vivas as tradições culturais, o artesanato, a gastronomia, ou seja, os usos e costumes de seus antepassados, bem como o patrimônio histórico e arquitetônico.

Concluímos que o turismo rural tem se desenvolvido nessa região como fonte importante de renda e de reorganização social do meio rural. Assim, as famílias rurais passam a depender não apenas do setor agrícola, mas de sua capacidade de executar outras atividades. Ao analisar a composição de atrativos da Rota Germânica do Rio Pardinho constatamos um aumento no número de atrativos na ordem de $70 \%$, desde sua criação. O mesmo ocorre com o Roteiro Caminhos da Imigração, que cresceu $122 \%$ no número de atrativos.

No Roteiro Caminhos da Imigração notamos o predomínio de pontos turísticos de caráter histórico e cultural. Igrejas e prédios antigos representam 80\% do número total de atrativos. Enquanto que na Rota Germânica do Rio Pardinho a proporção é inversa, ou seja, $65 \%$ dos atrativos estão relacionados à gastronomia, ao lazer e ao comércio de artesanato.

Podemos inferir que o turismo rural nessas regiões específicas contribui com o desenvolvimento regional, à medida que reduz o desemprego, o êxodo rural e com o aumento das rendas das famílias participantes. Por outro viés, reascende o sentimento de pertencimento, gerando comprometimento com o meio ambiente.

Percebemos que o fluxo de visitantes se dá em pequena escala, na maioria dos atrativos, o que não causa impacto significativo ao meio ambiente. Há ainda o cuidado, por parte de alguns agricultores familiares, em efetuar reservas e não exceder a capacidade de visitação em suas propriedades.

Diante desse contexto, coloca-se o desafio de acompanhar, por meio de novas pesquisas, as transformações que a atividade do turismo rural vai gerando em áreas rurais, particularmente em regiões de agricultura familiar, visando avaliar inclusive possíveis impactos decorrentes da intensificação da atividade e da possibilidade de extrapolamento do limite da capacidade de carga desses ambientes.

\section{Referências}

ACSELRAD, Henri. Sustentabilidade e articulação territorial do desenvolvimento brasileiro. In: II Seminário Internacional sobre Desenvolvimento Regional. Santa Cruz do Sul, RS, 2008.

ALMEIDA, J. A.; RIEDL, M. Apresentação. In: ALMEIDA, J. A.; FROEHLICH, J. M.; RIEDL, M. Turismo Rural e desenvolvimento sustentável. Santa Maria: UFSM, CCR, 1998.

BENI, Mário Carlos. Política e planejamento de turismo no Brasil. São Paulo: Aleph, 2006.

Análise estrutural do turismo. São Paulo: Editora SENAC São Paulo, 2002.

BENKO, Georges. Economia, espaço e globalização: na aurora do século XXI. Tradução: Antônio de Pádua Danesi. 2. ed. São Paulo: Hucitec, 1999. 
BLOS, Wladimir. O turismo rural na transição para um outro modelo de desenvolvimento rural. In: ALMEIDA, J. A.; RIEDL, M. (Org.). Turismo rural: ecologia, lazer e desenvolvimento. Bauru - SP, EDUSC, 2000.

BOISIER, Sergio. Em busca do esquivo Desenvolvimento Regional: entre a caixa-preta e o projeto político. Planejamento e Políticas Públicas, n. 13 (1996). Disponível em: <http://189.21.130.9/ppp/index.php/PPP/article/ viewFile/135/137>. Acesso em: 10 dez. 2016.

BRANDÃO, C. A. Teorias, estratégias e políticas regionais e urbanas recentes: anotações para uma agenda de desenvolvimento territorializado. Revista Paranaense de Desenvolvimento. Curitiba, n. 107, p. 57-76, jul./dez. 2004.

BRASIL, Lei 11.326/06. Disponível em <http://www.mda.gov.br/sitemda/noticias/ sancionada-lei-da-agricultura-familiar> Acesso em: 10 dez. 2016.

BURSZTYN, Marcel e BURSZTYN, Maria A. Fundamentos de política e gestão ambiental: os caminhos do desenvolvimento sustentável. RJ: Garamond, cap. 1, p. 31 - 64, 2012.

CARVALHO, Paulo G. M. e BARCELLOS, Frederico C. Mensurando a sustentabilidade. In: MAY, Peter (org.) Economia do meio ambiente: teoria e prática. 2a ed. São Paulo: Campus / Elsevier, cap. 5 , p. $99-132,2010$

CRISTÓVÃO, Artur. Mundo rural: entre as representações (dos urbanos) e os benefícios reais (para os rurais). In: RIEDL, Mário, ALMEIDA, Joaquim A., Viana, Andyara L. B. (Org.). Turismo rural: tendências e sustentabilidade. Santa Cruz do Sul, EDUNISC, 2002.

ETGES, Virginia E. A região no contexto da globalização: o caso do Vale do Rio Pardo. In: VOGT, O. P. e SILVEIRA, R. L. L. (Org). Vale do Rio Pardo: (re)conhecendo a região. Santa Cruz do Sul: EDUNISC, 2001.

Desenvolvimento regional sustentável: 0 território como paradigma. REDES, Santa Cruz do Sul, v.10, n.3, p. 47-55. set./dez. 2005.

FEE - Fundação de Economia e Estatística. Atlas socioeconômico do Rio Grande do Sul. Economia. Agricultura. Milho. Disponível em: <http://www.scp.rs.gov.br>. Acesso em: 10 dez. 2016.

GOMES, Antonio Carlos. A operacionalização do mercado institucional de alimentos no contexto do Vale do Rio Pardo: o caso da cooperativa Leoboqueirense de agricultores familiares. Dissertação (Mestrado em Desenvolvimento Regional) - UNISC, 2014. Orientadora: Prof. $\stackrel{\text { a }}{\text {. }}$ Dra ${ }^{\mathrm{a}}$. Cidonea Machado Deponti.
LATOUCHE, Serge. O decrescimento. Por que e como? In: LÉNA, Philippe e NASCIMENTO, Elimar Pinheiro (orgs.). Enfrentando os limites do crescimento: sustentabilidade, decrescimento e prosperidade. RJ: Garamond, cap. 2, p. $45-54,2012$.

MINAYO, Maria Cecilia de Souza. O desafio da pesquisa social. In: MINAYO, M. C. de Souza. (Org). Pesquisa Social: Teoria, método e Criatividade. Petrópolis, RJ: Vozes, 2010.

MINAYO, M. C. S. \& SANCHES, O. QuantitativoQualitativo: Oposição ou Complementaridade? Cad. Saúde Públ., Rio de Janeiro, 9 (3): 239262, jul/sep, 1993. Disponível em: < http://www.scielo.br/pdf/csp/v9n3/02.pdf>. Acesso em: 10 dez. 2016.

PECQUEUR, Bernard. A guinada territorial da economia global. Política \& Sociedade Revista de Sociologia Política, PPSP UFSC, 2009. Disponível em: $<$ http://www.periodicos.ufsc.br>. Acesso em: 10 dez. 2016.

RADÜNZ, Roberto. A organização cultural dos alemães no Vale do Rio Pardo. In: VOGT, O. P. e SILVEIRA, R. L. L. (Org). Vale do Rio Pardo: (re)conhecendo a região. Santa Cruz do Sul: EDUNISC, 2001.

SANTOS, Milton. O Papel ativo da Geografia - um manifesto. In: XXI Encontro Nacional de Geógrafos. Florianópolis - Julho de 2000. Disponível em: <http://www.revistaterritório.com.br/pdf/09_7_s antos.pdf>. Acesso em: 10 dez. 2016.

A natureza do espaço: técnica e tempo, razão e emoção. São Paulo: Hucitec, 1997.

SEN, Amartya Kumar. Desenvolvimento como liberdade. São Paulo: Companhia das Letras, 2000.

SEPLAG. Secretaria do Planejamento, Gestão e Participação Cidadã. Rumos 2015. Disponível em: <http://www.seplag.rs.gov.br>. Acesso em: 10 dez. 2016.

SILVA J. Graziano da e CAMPANHOLA, C. O Novo Rural Brasileiro: Uma Análise Nacional e Regional. Campinas, EMBRAPA/UNICAMP. (4 volumes), 2000.

SOUZA, Renato S. Entendendo a questão ambiental: temas de economia, política e gestão do meio ambiente. Santa Cruz do Sul: EDUNISC, Apêndice cap. 3, p. 119 - 140, 2000.

VOGT, Olgário Paulo. Formação social e econômica da porção meridional do Vale do Rio Pardo. In: VOGT, O. P. e SILVEIRA, R. L. L. (Org). Vale 
do Rio Pardo: (re)conhecendo a região. Santa Cruz do Sul: EDUNISC, 2001.

ZANCHI, Verenice. Roteiros de turismo rural na região dos Vales do Rio Pardo e Taquari - RS. 2013. 134 f. Dissertação (Programa de Pósgraduação em Desenvolvimento Regional Mestrado e Doutorado) - Universidade de Santa Cruz do Sul, Santa Cruz do Sul, 2013. 